$\underline{\text { Iranian Journal of Pathology }}$ | ISSN: 2345-3656

\title{
Sarcomatoid Carcinoma of Renal Pelvis Involving Ureter and Renal Parenchyma with Heterologous Osteosarcomatous Differentiation: A Case Report and Review of Literature
}

\author{
Bhavya P. Mohan ${ }^{1 *}$, Jayalakshmy PL ${ }^{1}$, Letha $V^{1}$, Suresh Bhat ${ }^{2}$ \\ 1. Dept. of Pathology, Government Medical College, Kottayam, Kerala, India \\ 2. Dept. of Genitourinary Surgery, Government Medical College, Kottayam, Kerala, India
}

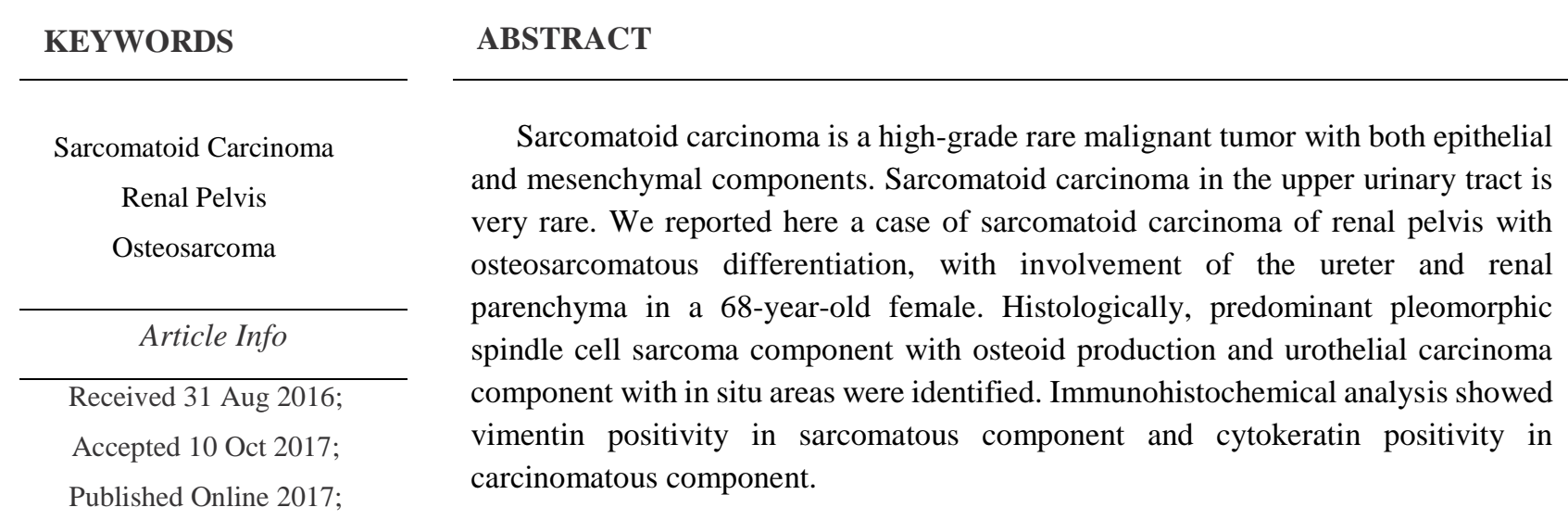

Corresponding Information:Dr.Bhavya P.Mohan, Assistant Professor, Pathology, Medical college, Kottayam, E-mail: bhavyasharath80@gmail.com

Copyright (C) 2017, IRANIAN JOURNAL OF PATHOLOGY. This is an open-access article distributed under the terms of the Creative Commons Attributionnoncommercial 4.0 International License which permits copy and redistribute the material just in noncommercial usages, provided the original work is properly cited.

\section{Introduction}

Sarcomatoid carcinoma is a rare high-grade malignant neoplasm with morphological and/or immunohistochemical evidence of both epithelial and mesenchymal differentiation. Sarcomatoid carcinoma can occur in many organs including the bladder, breast, female genital tract, oesophagus, kidney and larynx $(1,2)$. The urinary bladder is the predominant site of its occurrence in the urinary tract (3). Sarcomatoid carcinoma of renal pelvis (SCRP) is extremely rare (4). Surgical resection is the treatment of choice at present. Because of the rare nature of SCRP and its poor response to adjuvant therapy, early pathologic diagnosis is crucial to improve patients' survival. Thorough histopathological evaluation together with immunohistochemistry is essential for accurate diagnosis of this biphasic tumor. To the best of our knowledge, only less than 30 cases of sarcomatoid carcinoma of the renal pelvis have been published in English literature and only two of them showed osteosarcomatous differentiation (3). Here, we reported a case of sarcomatoid carcinoma arising in renal pelvis, involving ureter and renal parenchyma, with osteosarcomatous differentiation at all the three sites.

\section{Case report}

A 68-year-old female presented with a history of painless haematuria associated with passage of clots for one month. She was catheterised following an episode of acute urinary retention 3 weeks back. She had a history of diabetes and hypertension. There was no abdominal mass on palpation. The haemoglobin level was $11.2 \mathrm{~g} / \mathrm{dL}$. Other haematological and biochemical parameters were within the normal limits. Urine cytology had negative results regarding malignant cells. Spiral computed tomography scan of abdomen and pelvis with urogram revealed a large heterogeneously enhancing infiltrative lesion with specks of calcification in the pelvicalyceal system of the left kidney infiltrating into the left renal cortex and upper half of the ureter with hydronephrosis and hydroureter (Figure.1). 


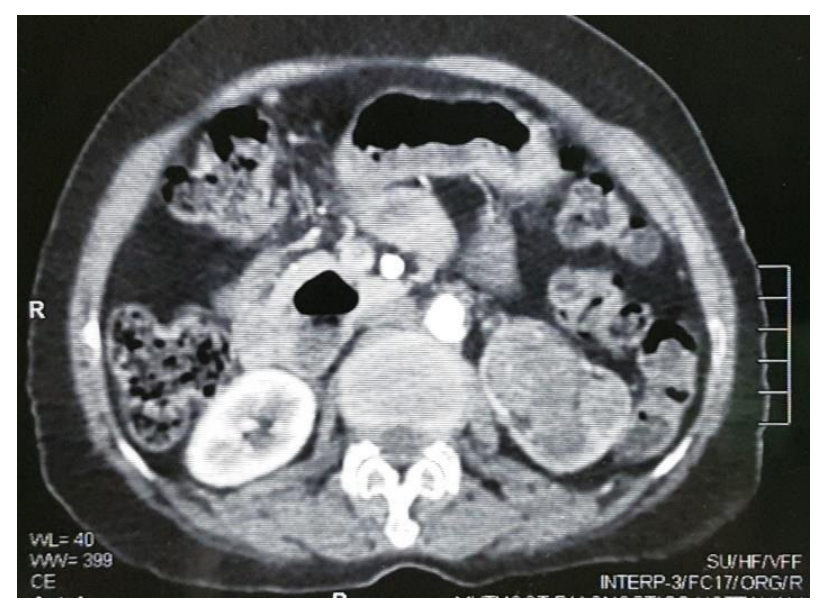

Fig 1. CT scan showing large heterogeneously enhancing mass lesion in the pelvicalyceal system of the left kidney infiltrating into left renal cortex.

Left nephroureterectomy was performed with a preoperative diagnosis of transitional cell carcinoma.

Gross pathology; resected nephrectomy specimen measuring $12 \mathrm{~cm} \times 5 \mathrm{~cm} \times 4 \mathrm{~cm}$ with attached ureter measuring $10 \mathrm{~cm}$. External surface of the kidney was covered with perinephric pad of fat and appeared smooth and nonadherent. Cut surface of the kidney showed a polypoidal whitish solid homogeneous growth in the pelvic region measuring $10 \mathrm{~cm} \times 4.5 \mathrm{~cm} \times 3 \mathrm{~cm}$ extending to the renal parenchyma. The corticomedullary differentiation was retained in the adjacent renal parenchyma. The tumor also involved the ureter with marked dilatation, irregular nodularities on the surface of upper ureter, wall thickening and intraluminal extension (Figure 2a).

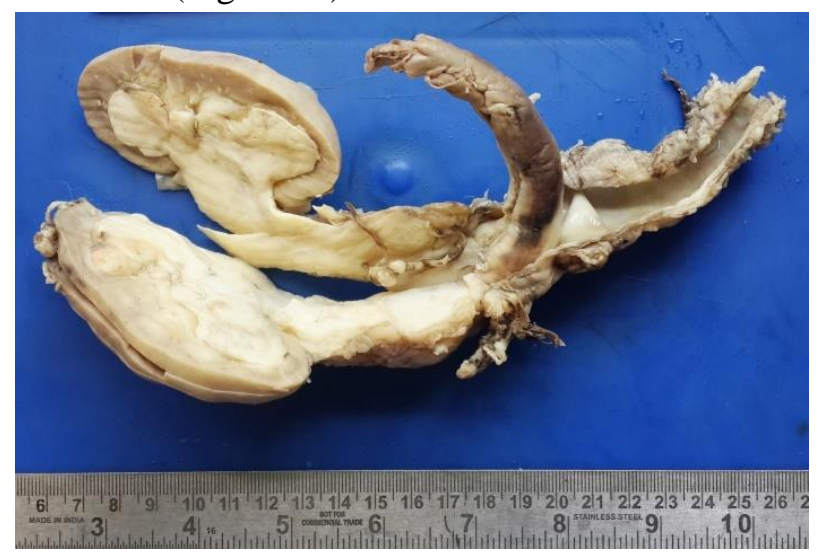

Fig 2a. Gross specimen with whitish solid mass in renal pelvis, ureter and kidney

The resected end of the ureter, renal capsule and vessels were free of tumor.
Microscopy showed a neoplasm composed predominantly of sheets and poorly formed fascicles of pleomorphic spindle cells with vesicular nuclei and nucleoli.

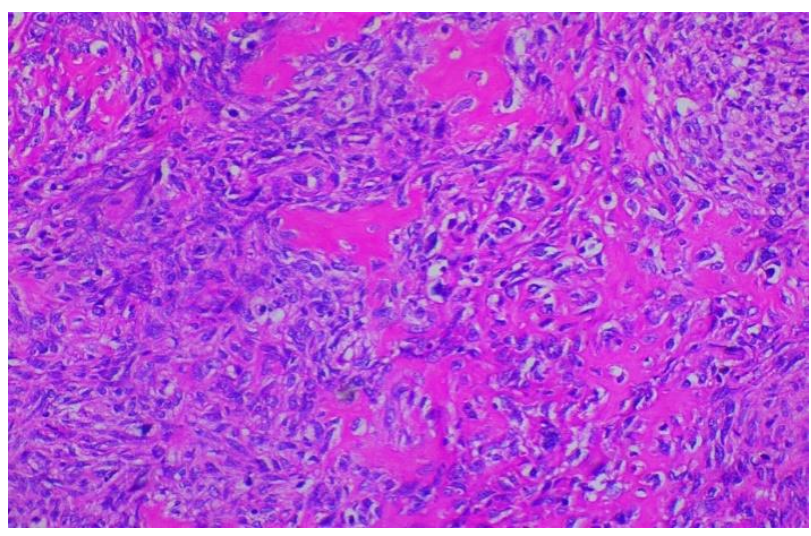

Fig 2b. Section showing sarcomatous area with abundant osteoid production (H\&E stain X 200)

Extensive foci of osteosarcomatous differentiation was noted with abundant osteoid matrix production and areas of mineralised osteoid (Figure 2b).

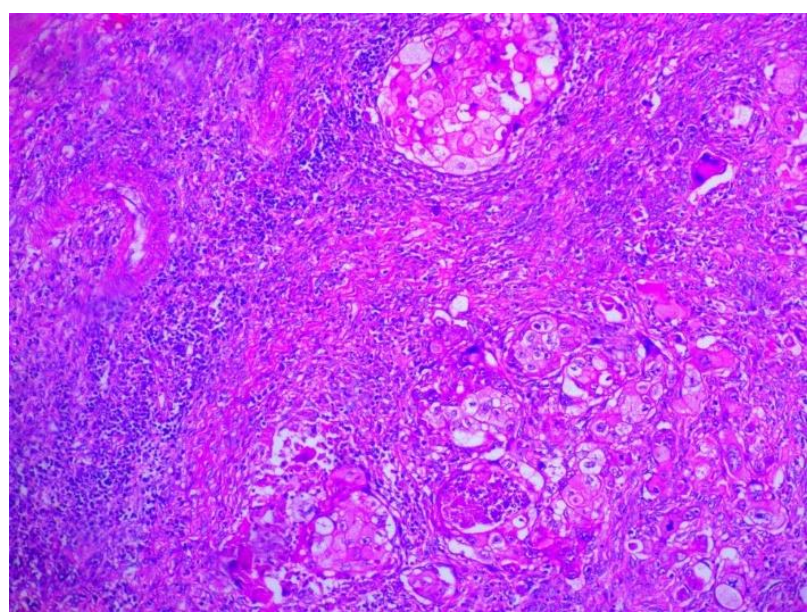

Fig 2c. Section showing areas of urothelial carcinoma forming epithelial component (H\&E stain X 100).

6-8 mitotic figures/high power field with atypical mitosis, tumour giant cells, foci of necrosis, calcification and hyalinisation were also noted. The tumour involved renal parenchyma and ureter with osteosarcomatous differentiation at both sites. The focal epithelial component was formed by islands of urothelial carcinoma with carcinoma in situ in the urothelium of renal pelvis (Figure 2c, 2d). 


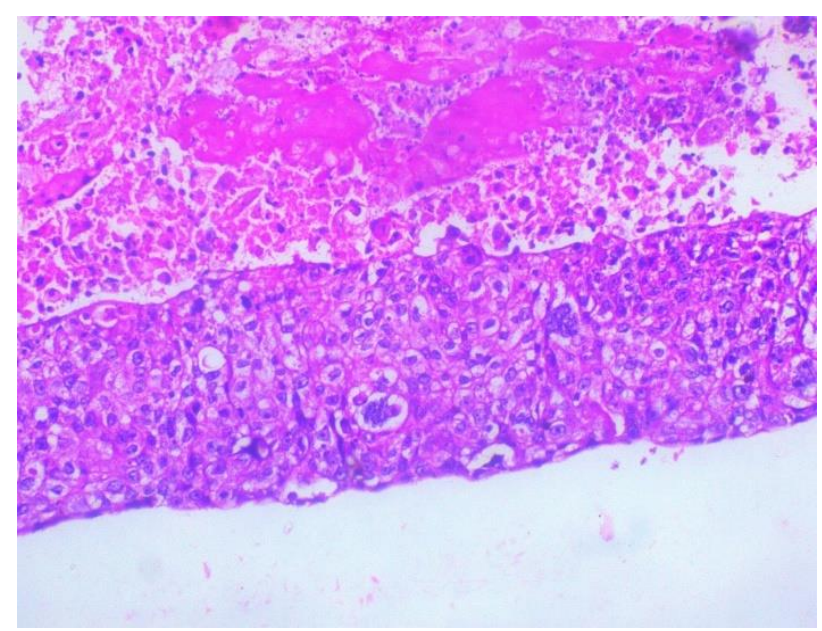

Fig 2d. Section showing focus of urothelial carcinoma in situ with marked pleomorphism (H\&E stain X 200)

Immunohistochemistry was performed and epithelial elements were found to have strongly positive results for cytokeratin and negative for vimentin. The sarcomatous component was found to have positive results for vimentin (Figure $3 \mathrm{a}, \mathrm{b}$ ).

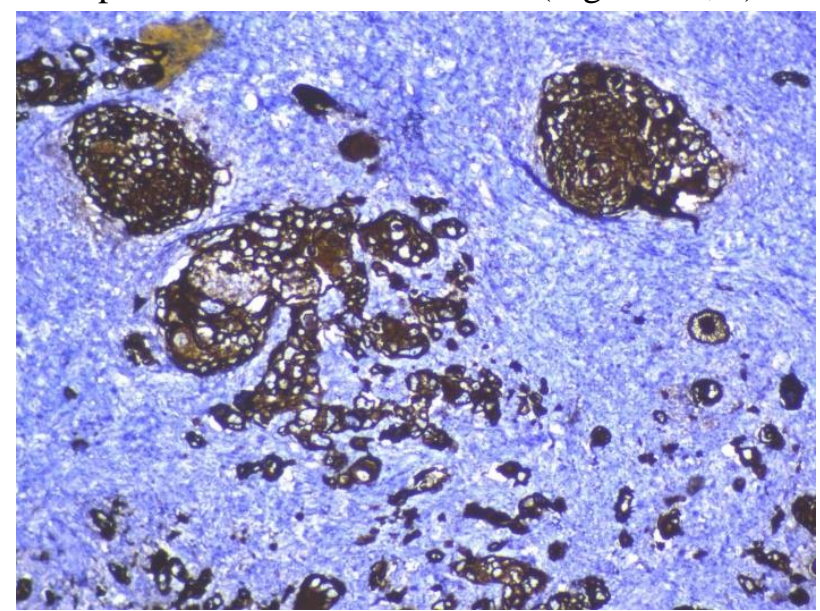

Fig 3a. Immunostain (x 200 magnification) showing strong cytokeratin positivity in epithelial component and negativity in spindle cell areas.

A pathological diagnosis of sarcomatoid carcinoma of renal pelvis with osteosarcomatous differentiation with involvement of the ureter and renal parenchyma was given. The resected end of the ureter, renal capsule and vessels were free of tumor. The postoperative period was uneventful and the patient was discharged 8 days after the operation. Ten months later the patient was receiving regular clinical follow-up and there was no evidence of local or metastatic disease.

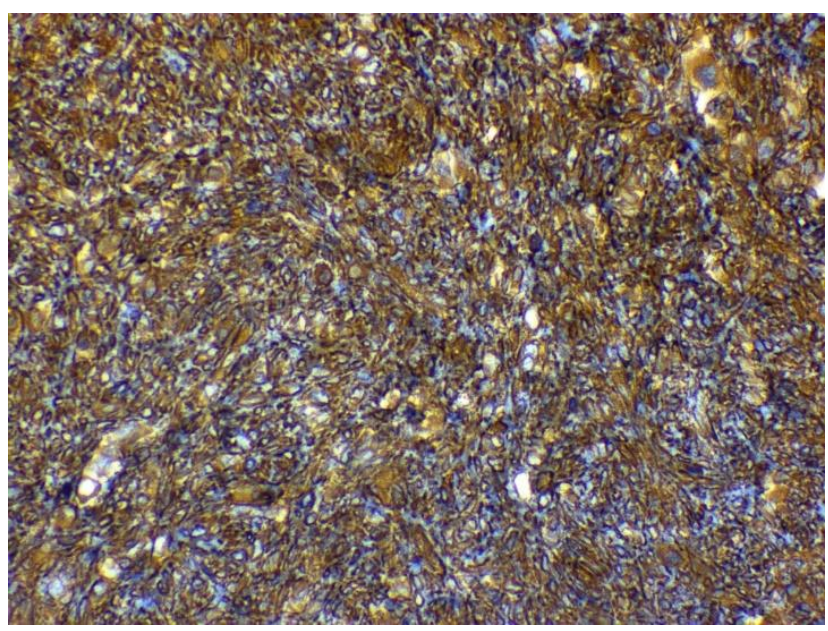

Fig 3b. Immunostain (x 200 magnification) showing vimentin positive sarcomatous areas

\section{Discussion}

As per the World Health Organization Classification of Tumours (2016), "sarcomatoid carcinoma" (also called carcinosarcoma) is a biphasic malignant neoplasm exhibiting epithelial and mesenchymal differentiation (1). Immunohistochemically, epithelial elements react with cytokeratins and sarcomatous elements react with vimentin or other mesenchymal specific markers.

SCRP is a very rare entity. The first true case of sarcomatoid carcinoma in the renal pelvis was reported by Piscioli et al. (2). To the best of our knowledge, only less than 30 cases of sarcomatoid carcinoma of the renal pelvis have been reported in English literature (Table 1).

The age range of onset for this tumour is $38-85$ years with a male-to-female ratio of 4-5:1. Presenting symptoms include gross haematuria, flank pain, abdominal mass, dysuria and acute urinary retention. Our patient was a 68 -year-old female and presented with gross haematuria and acute urinary retention. 
Table 1. Characteristics of previous reported cases of SCRP

\begin{tabular}{|c|c|c|c|}
\hline Authors & Year & Salient features & $\begin{array}{l}\text { No. of } \\
\text { cases }\end{array}$ \\
\hline Piscioli et al. & 1984 & 62/M; TCC/rhabdomyosarcomatous tumor-like & 1 \\
\hline Wick et al. & 1985 & 45/M; TCC/Anaplastic spindle cell sarcoma in 1 case; SCC/spindle in other case & 2 \\
\hline Tajima Y et al. & 1988 & $\begin{array}{l}\text { 66/M; Renal pelvic tumor containing transitional cell carcinoma, adenocarcinoma } \\
\text { and sarcomatoid elements }\end{array}$ & 1 \\
\hline Suster S et al. & 1989 & $\begin{array}{l}\text { 85/M; Spindle cell carcinoma of the renal pelvis demonstrating coexpression of } \\
\text { keratin and vimentin intermediate filaments }\end{array}$ & 1 \\
\hline Lopez Beltran et al. & 1996 & $\begin{array}{c}\text { Mean age 71.6years; } \mathrm{M}: \mathrm{F}=3: 2 ; \text { mean survival after onset of symptoms } 11.2 \text { months; } \\
\text { Spindle/anaplastic in 3cases; spindle/myxoid in } 2 \text { cases }\end{array}$ & 5 \\
\hline Vermeulen $P$ et al. & 2000 & $\begin{array}{l}\text { Biphasic sarcomatoid carcinoma of the right kidney with chondrogenic } \\
\text { differentiation }\end{array}$ & 1 \\
\hline Hisataki et al. & 2001 & 43/F; TCC/spindle; in a duplicated renal pelvis & 1 \\
\hline M. F. Acikalin et al. & 2005 & 66/M; SCRP with Giant Cell Tumour like Features & 1 \\
\hline Thiel DD et al. & 2006 & 65/M; Renal pelvis confined sarcomatoid carcinoma of transitional cell origin. & 1 \\
\hline Yu-Li Lin, et al. & 2008 & $67 / F ;$ TCC in situ and another sarcoma-like area with prominent spindle cells & 1 \\
\hline Chen GM et al. & 2011 & 77/M; SCRP in duplex kidney & 1 \\
\hline S. Gill Samra et al. & 2012 & $\begin{array}{l}\text { 76/F; Sarcomatoid carcinoma involving the renal pelvis and ureter with } \\
\text { heterologous osteosarcomatous differentiation }\end{array}$ & 1 \\
\hline Chen S et al. & 2013 & $\begin{array}{c}\text { Age range } 38-78 \text { years; All males; Tumor size range } 1.5-16 \mathrm{cms} \text {. A spindle cell } \\
\text { carcinoma without apparent epithelial elements in } 1 \text { case, spindle and TCC in } 4 \\
\text { cases, spindle and SCC in } 3 \text { cases. }\end{array}$ & $\begin{array}{l}8 \text { (over a } \\
10 \text { year } \\
\text { period) }\end{array}$ \\
\hline Hye In Ahn et al. & 2013 & $\begin{array}{c}\text { 68/M; Sarcoma with exuberant osteosarcomatous element and papillary urothelial } \\
\text { carcinoma }\end{array}$ & 1 \\
\hline Xiquan Tian et al. & 2014 & $\begin{array}{c}\text { 49/F; Pleomorphic sarcoma with multinucleate giant cells and high grade urothelial } \\
\text { carcinoma }\end{array}$ & 1 \\
\hline $\begin{array}{l}\text { Ramakrishnan D et } \\
\text { al. }\end{array}$ & 2014 & $\begin{array}{l}\text { 49/M; Urothelial carcinoma arising in the renal pelvis with exuberant } \\
\text { chondrosarcomatous element associated with adrenal metastasis }\end{array}$ & 1 \\
\hline
\end{tabular}

IHC: Immunohistochemistry; TCC: Transitional cell carcinoma; SCC: Squamous cell carcinoma; M: Male; F: Female; SCRP: Sarcomatoid carcinoma of renal pelvis

In most of the cases, the epithelial component was urothelial carcinoma with squamous or glandular differentiation and the mesenchymal element was poorly or undifferentiated spindle cells with or without heterologous elements (5). The peculiar histologies reported in association with sarcoma component were rhabdomyosarcomatous, giant cell tumour like, myxoid, osteoclast rich and chondrosarcomatous types $(3,4,6,7)$. Our case showed a predominant component of pleomorphic sarcoma with osteosarcomatous differentiation with abundant osteoid matrix production which is extremely rare at this site. Moreover, both ureter and renal parenchyma were involved by osteosarcomatous component. The focal epithelial component was formed by islands of urothelial carcinoma with in situ carcinoma of urothelium of renal pelvis. Immunohistochemical analysis showed vimentin positivity in sarcomatous component and cytokeratin positivity in carcinomatous component. Only two cases of sarcomatoid carcinoma of renal pelvis with osteosarcomatous differentiation have been published so far (3). It is almost impossible to reach a correct preoperative diagnosis of SCRP, due to the lack of distinctive clinical or radiological features. The accurate diagnosis is often made by histological features and immunohistochemical findings, postoperatively.

The exact pathogenesis of sarcomatoid carcinoma has been a matter of controversy (9). The monoclonal theory about its pathogenesis states that both carcinomatous and sarcomatous tumour cells 
are derived from a single pluripotent stem cell that undergoes divergent epithelial and mesenchymal differentiation. Sung et al. (9) supported monoclonal cell origin of sarcomatoid carcinoma and suggested that clonal divergence may occur during tumour progression and differentiation by demonstrating identical pattern of non-random X-chromosome inactivation and significant overlap of loss of heterozygosity in both carcinomatous and sarcomatous components.

The differential diagnoses include true sarcomas, sarcomatoid renal cell carcinomas and nonneoplastic lesions such as inflammatory pseudo tumour. Sometimes, differentiating the origin of sarcomatoid carcinoma as either a primary renal or urothelial tumor is difficult. Demonstration of carcinoma in situ change in the urothelium and immunohistochemical staining of PAX8 and the transcription factor GATA3 can be of use in identifying the origin (10).

Sarcomatoid carcinoma is a high grade tumor associated with recurrences and metastasis. A poor prognosis has been reported for most patients with very few exceptions $(5,8,11)$. Our patient did not receive any adjuvant therapy. She was on regular follow-up 10 months later and there was no evidence of local recurrence or metastasis.

In conclusion, we presented a case which is extremely rare. Though rare, SCRP should be considered in the differential diagnosis of tumors of renal pelvis. Thorough sampling of renal pelvic tumours to demonstrate biphasic elements and carcinoma in situ component and using appropriate immunohistochemistry panel would help in diagnosis.

\section{References}

1. H. Moch, P.A. Humphrey, T. M. Ulbright, V. E. Reuter. World Health Organization Classification of Tumours of the Urinary System and Male Genital Organs. Lyon: IARC Press; 2016, p.151.

2. Piscioli F, Bondi A, Scappini P Luciani L.True sarcomatoid carcinoma of the renal pelvis. First case report with immunocytochemical study. Eur Urol 1984; 10:350-5.

3. H. Ahn, J. Sim, H. Han, H. Kim, K. Yi, Y. Jun et al. A Case Report of a Sarcomatoid
Carcinoma Arising in the Renal Pelvis with Exuberant Osteosarcomatous Element. O J Pathology 2013;3(2): 96-8.

4. M. F. Acikalin, S. Kabukcuoglu, C. Can. Sarcomatoid Carcinoma of the Renal Pelvis with Giant Cell Tumour like Features: Case Report with Immunohistochemical Findings. Int J Urol 2005; 12(2):199-203.

5. Chen S, Chen G, Xia D, Li J, Wang S, Shen B, et al. Sarcomatoid carcinoma of the renal pelvis: Experience of multiple cases over a ten-year period. Oncol Lett 2013; 6:513-6.

6. Xiquan Tian, Jiyu Zhao, Yue Wang, Nianzeng Xing. Sarcomatoid carcinoma of the renal Pelvis: A case report. Oncol Lett 2014; 8:1208-10.

7. Ramakrishnan D, Subachitra T, Padmavathi R, Devi GD. A case report of an urothelial carcinoma arising in the renal pelvis with exuberant chondrosarcomatous element associated with adrenal metastasis. Indian J Pathol Microbiol 2014; 57:284-6.

8. Lopez-Beltran A, Escudero AL, Cavazzana AO, Spagnoli LG, Vicioso Recio L. Sarcomatoid transitional cell carcinoma of the renal pelvis. A report of five cases with clinical, pathological, immunohistochemical and DNA ploidy analysis. Pathol Res Pract 1996; 192:121824.

9. M. T. Sung, M. Wang, G. T. MacLennan, J. N. Eble, P. H. Tan, A. Lopez-Beltran et al. R. Histogenesis of Sarcomatoid Urothelial Carcinoma of the Urinary Bladder: Evidence for a Common Clonal Origin with Divergent Differentiation. J Pathol 2007; 211(4): 420-30.

10. Chang A, Brimo F, Montgomery EA and Epstein JI: Use of PAX8 and GATA3 in diagnosing sarcomatoid renal cell carcinoma and sarcomatoid urothelial carcinoma. Human Pathology 2013; 44: 1563-68.

11. Thiel $\mathrm{DD}$, Igel $\mathrm{TC}$ and $\mathrm{Wu} \mathrm{KJ}$ : Sarcomatoid carcinoma of transitional cell origin confined to renal pelvis. Urology 2006; 67:622. 